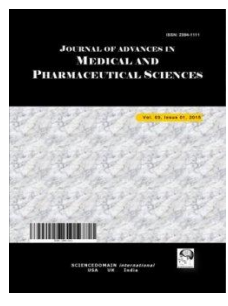

\title{
Journal of Advances in Medical and Pharmaceutical Sciences
}

19(1): 1-7, 2018; Article no.JAMPS.45725

ISSN: 2394-1111

\section{Exploring the Knowledge, Attitude and Practices towards Use of Unprescribed Drugs among Adults of a Selected City of Somaliland}

\author{
Salman Mohamed Farah ${ }^{1^{*}}$, A. B. M. Alauddin Chowdhury1, Kamrul Hossain², \\ Masoud Mohammadnezhad ${ }^{3}$ and Russell Kabir ${ }^{4}$ \\ ${ }^{1}$ Department of Public Health, Daffodil International University, Dhaka, Bangladesh. \\ ${ }^{2}$ Department of General Educational Development, Daffodil International University, Dhaka, \\ Bangladesh. \\ ${ }^{3}$ Department of Public Health and Primary Care, Fiji National University, Fiji. \\ ${ }^{4}$ School of Allied Health, Anglia Ruskin University, Chelmsford, Essex, UK.
}

Authors' contributions

This work was carried out in collaboration between all authors. Author SMF designed the study, performed the statistical analysis, wrote the protocol and wrote the first draft of the manuscript. Authors ABMAC and KH managed the analyses of the study. Authors MM and RK managed the literature searches. All authors read and approved the final manuscript.

Article Information

DOI: 10.9734/JAMPS/2018/45725

Editor(s):

(1) Dr. Claudia Borza, Department of Pathophysiology, "Victor Babes" University of Medicine and Pharmacy, Romania. (2) Dr. Robert Dymarek, Department of Nervous System Diseases, Wroclaw Medical University, Poland.

(1) Camilo Torres-Serna, Universidad del Valle and Santiago de Cali University, Colombia.

(2) Salime C. Hadad, Brazil. Complete Peer review History: http://www.sciencedomain.org/review-history/27869

Original Research Article

Received 15 September 2018

Accepted 04 December 2018

Published 19 December 2018

\begin{abstract}
Background: The emergence and spread of resistance related to the irrational use of antibiotics is a major global public health problem. The aim of this study was to assess Knowledge, Attitude and Practices towards use of unprescribed drugs among adults in a selected city of Somaliland.

Methods: This study used cross-sectional survey and data was collected through semi-structured questionnaire. A purposive sampling of 400 individuals was obtained; Slovene's Formula was used to calculate the sample size \& Data was analysed by using SSPS v.20 and Ms Excel.

Results: It is found that $64.3 \%$ of the respondents used any form of medicine without a medical practitioner's prescription. It is found that there is a significant association between respondent's level of knowledge and practice of unprescribed drug use.
\end{abstract}


Conclusion: The conclusion is that it is important to formulate policies and strategies for drug distribution and sales aimed for controlling the public use of unprescribed drugs.

Keywords: Knowledge; attitude and practice; antibiotics; unprescribed drugs; adults; Somaliland.

\section{INTRODUCTION}

An unprescribed drug also called over the counter (OTC) refers to drugs that can be obtained without a medical prescription or drugs that are safe and effective for use by the general public without seeking treatment by a health professional [1]. The emergence and spread of resistance related to the irrational use of antibiotics is a major global public health problem. Studies from American, Asian and European countries indicate that between 22\% and $70 \%$ of parents have misconceptions about the appropriate applications and efficacy of antibiotics and often use them without a prescription. A study found that other determinants of self-medication with antibiotics in low-income countries include over-the-counter sales of antibiotics, the high cost of medical consultations and dissatisfaction with medical practitioners [2].

It has been estimated that more than $50 \%$ of antibiotics are purchased without a prescription and used over-the-counter in most parts of the world [3] and like antibiotics, anti ulcerants are overprescribed drugs worldwide both at primary and secondary care [4]. The World Health Organization estimates that more than half of all medicines are inappropriately prescribed, dispensed or sold. In addition, half of all patients fail to take them correctly [5]. The situation in developing countries is of particular concern because the use of antibiotics without medical guidance is largely influenced by the use of the private healthcare system. A disadvantage of this system is that the availability of drugs without prescription becomes ordinary with inadequate regulation of the distribution and sale of drugs [6]. The general population can play an important role in reducing the inappropriate and excessive utilisation of antibiotic and it is necessary to understand their antibiotic use knowledge, attitudes, and practices and if any educational needs exist [7].

In Somaliland which is now recovered from the destructions and started the way to development and social service improvement there is scarcity of information in this regard. The pharmaceutical sector of Somaliland is least invested, and the pharmacist should distinguish between prescribed and non-prescribed drugs also the wholesalers have no permit selling drugs on retail [8]. the government of Somaliland have been starting to rebuild health care facilities and hospitals, which made progress for the protection of people's health, including mother and child health, but still public health issues and drug regulation is under progress. Recently, selfmedication practices spread and became more of a phenomenon in the community of Somaliland, due to lack of public health laws in the country [9].

The research findings will help policy makers to develop proper strategies to understand as well as to improve the factors which are associated with the increasing use of unprescribed drugs. The aim of this study was to assess level of Knowledge, Attitude and Practices towards use of Unprescribed drugs among adults (15 years or older) in a selected City of Somaliland.

\section{MATERIALS AND METHODS}

This study was cross sectional study conducted at Hargeisa city from May to September 2014. Hargeisa is the capital city of the Republic of Somaliland it is composed of five major districts and hosts around 1, 000,000 people. The sampling unit was individual and purposive sampling was used to select the participants. Every person who was aged 15 years or older which resides in Hargeisa city and available at the time of study was included in this study, while every person who was sick and or who refused to participate during the study was excluded.

In this research, sample size was 400 individuals who were selected purposively from different districts of Hargeisa city. The research instrument was a self-administered semistructured questionnaire. The first part of the tool was demographic data including: age, sex, marital status, educational level, occupation. The second part of the tool included the knowledge related questions (knowledge of using prescribed drugs, knowledge of the health consequences unprescribed drugs has, knowledge of the types of health consequences). 
The third part of the tool included Attitude related questions (Somaliland's regulation against drug distribution and sales, best prevention measures of the consequences that unprescribed drugs usage has). The fourth part of the tool included practices related questions (used any drugs without a medical practitioner's prescription, types of unprescribed drugs you mostly use).

The researcher was responsible for collecting the completed questionnaires from the respondents. The questionnaire took approximately 15 minutes to be completed. Data was analysed by using SPSS v.20 and MS Excel. Simple frequencies, means and standard deviations were utilised for continuous variables. Bivariate analyses like chisquare were done as appropriate. All participants in this study signed a written consent form. The ethical approval was obtained from the Daffodil International University Research Ethics Committee and Ethics Committee of Hargeisa city, Somali Land prior to the start of data collection.

\section{RESULTS}

It is found that about $40.8 \%$ of the respondents were male followed by $59.3 \%$ females. Additionally, this table shows that almost near to half of the respondents $(48.3 \%)$ were older than 30 years of age, followed by $28 \%$ of the respondents who were aged 21-30 years of age and $23.5 \%$ who were $15-20$ years old. Added to this, the results demonstrate that slightly more than half of the respondents $(50.3 \%)$ were married, followed by $35.5 \%$ who were single, $8 \%$ who were divorced and $6.3 \%$ who were widow/er as shown in Table 1.

Approximately $21.8 \%$ of the respondents were illiterate followed by $23 \%$ who have educational level of Up to grade school, $23 \%$ who have educational level of Up to secondary school, $16.3 \%$ who have educational level of Up to college degree, $16 \%$ who have educational level of Up to graduate degree. Additionally, the findings show that more than half of the respondents $(53.6 \%)$ were unemployed, followed by $24.3 \%$ who were self-employed, $20.5 \%$ who were employee and $1.5 \%$ who belong to other kinds of occupation as presented in Table 2.

The respondents were knowledgeable about the health harms of the unprescribed drug use is shown in Table 3. Added to this, it displays that almost $39.8 \%$ of the respondents stated that use of unprescribed drugs are important followed by
$19.8 \%$ who said it is not important and $40.3 \%$ who said it is risky. The results also show $19.3 \%$ of the respondents agreed that use of unprescribed drugs improves health, followed by $65.8 \%$ who disagreed that use unprescribed drugs improves health and $14.8 \%$ were uncertain about this regard. Additionally, the possibility of unprescribed drug use by the respondents if it had not had any impact and the result was that $35.8 \%$ prefer to take, followed by $48.3 \%$ who disagreed to take and $15.8 \%$ who were uncertain about this regard.

Almost $35.1 \%$ of the respondents stated that the Republic of Somaliland has a reliable regulation against drug sales and distribution, followed by $28 \%$ who said the regulation is unreliable and $36.8 \%$ said the regulation against drug sales and distribution is poor. Added to this, more than half of the respondents $(56.8 \%)$ suggested that health education is the best way to prevent use of unprescribed drugs, followed by $37 \%$ suggested that rule and regulation is the best way to prevent use of unprescribed drugs and $6 \%$ of them suggested combining both rule/ regulation and health education is the best way to prevent use of unprescribed drugs. Additionally, more than seven tenths of the respondents think that it is important to stop and prevent use of unprescribed drugs, followed by $23.1 \%$ which think that use of unprescribed drugs is risky, $2 \%$ think it is normal, and $3.5 \%$ think that government must control as shown in Table 4.

Almost $64.3 \%$ of the respondents used a medicine without a medical practitioner's prescription followed by $35.5 \%$ who did not use. The finding also shows $61.3 \%$ of the respondents were used unprescribed drugs more than one time, followed by $38.5 \%$ who did not use unprescribed drugs more than one time. This study also find out the types of OTC used by the respondents which are $19.6 \%$ of the respondents used Antibiotics, followed by $47 \%$ who used Anti pain, $5 \%$ who used Sedatives and $28.3 \%$ who used other medications as shown in Table 5.

Table 6 shows that there is significant association between knowledge of the health consequences and practices of unprescribed drugs.

\section{DISCUSSION}

This study looked into the prevalence of unprescribed drug usage among adults of Hargeisa city. The respondents were 
knowledgeable about the health harms of the unprescribed drug use similar finding were also stated by other research in Mongolia [2]. People prefer to take unprescribed drugs for emergency medical needs like Anti pain for headache, toothache, muscle pain etc. The results indicate that unprescribed drug users among the respondents in our study was $64.3 \% \%$. This prevalence is remarkably higher than the reports from study conducted in USA where prevalence of non-prescribed use of pain relievers in their lifetime was approximately one in 10 adolescents aged 12-17 years [10].

Approximately half of the respondents used anti pain medications mostly without medical practitioner's prescription. The study revealed that nearly two-fifths $(39.8 \%)$ of the respondents stated that use of unprescribed drugs are important. Near to one-fifth $(19.3 \%)$ of the respondents agreed that use of unprescribed drugs improves health and $35.8 \%$ of the respondents prefer to use unprescribed drugs if it had not had any impact. The bivariate analysis found that there is significant association between knowledge of the health consequences and practices of unprescribed drugs, this is similar to a study conducted in China demonstrated that low level of knowledge associated with antibiotic use [11].

The prevalence of unprescribed drug usage among adults of Hargeisa city was (64.3\%) this is remarkably higher than the findings of another study conducted in Mongolia [2]. And it is associated with availability, cost effectiveness and lack of proper regulation of drug distribution and sales. The results suggest formulating policies and strategies for drug distribution and sales.

Table 1. Distributions of the respondents by sex, age and marital status

\begin{tabular}{lll}
\hline Variable & Frequency $\mathbf{( n = 4 0 0 )}$ & Percentage (\%) \\
\hline Sex & 163 & \\
Male & 237 & 50.8 \\
Female & & 59.3 \\
Age ( years) & 94 & 23.5 \\
$15-20$ & 112 & 28 \\
$21-30$ & 193 & 48.3 \\
$>30$ & & \\
Marital status & 142 & 35.5 \\
Single & 201 & 50.3 \\
Married & 32 & 8 \\
Divorced & 25 & 6.3 \\
Widow/er & & \\
\hline
\end{tabular}

Table 2. Distributions of the respondents by level of knowledge and occupation

\begin{tabular}{lll}
\hline Variable & Frequency $(\mathbf{n}=\mathbf{4 0 0})$ & Percentage $\mathbf{( \% )}$ \\
\hline Level of education & & \\
Illiterate & 87 & 21.8 \\
Up to grade school & 92 & 23 \\
Up to secondary school & 92 & 23 \\
Up to college degree & 65 & 16.3 \\
Graduate degree & 64 & 16 \\
Occupation & & \\
Unemployed & 214 & 53.6 \\
Self employed & 97 & 24.3 \\
Employee & 82 & 20.5 \\
Others & 6 & 1.5 \\
\hline
\end{tabular}


Table 3. Respondent's Knowledge of unprescribed drugs

\begin{tabular}{lll}
\hline Variable & $\begin{array}{l}\text { Frequency } \\
\text { (n=400) }\end{array}$ & $\begin{array}{l}\text { Percentage } \\
\text { (\%) }\end{array}$ \\
\hline Respondent's knowledge of prescribed drug use & 148 & 37 \\
Excellent & 152 & 38.1 \\
Good & 99 & 24.8 \\
poor & & \\
Knowledge of side effects of unprescribed drugs use & 304 & 76 \\
Good & 95 & 23.8 \\
Poor & 59 & 14.8 \\
Knowledge of consequences that unprescribed drugs can cause & 13.8 \\
Toxicity & 55 & 9.3 \\
Decreases immunity & 37 & 62 \\
Abortion in pregnant women & 248 & \\
All & & 39.8 \\
Use of unprescribed drugs are & 159 & 19.8 \\
Important & 79 & 40.3 \\
Not important & 161 & \\
Risky & & 19.3 \\
Use of unprescribed drugs improves health & 77 & 65.8 \\
Agree & 263 & 14.8 \\
Disagree & 59 & \\
Uncertain & & 27.5 \\
I like use of unprescribed drugs & 110 & 72.3 \\
Yes & 289 & 35.8 \\
No & 143 & 48.3 \\
Prefer to take unprescribed drugs If there is no consequences & 15.8 \\
Agree & 63 & \\
Disagree & & \\
Uncertain & & \\
\hline & & \\
\hline
\end{tabular}

Table 4. Respondent's Attitude towards consequences of unprescribed drugs and its regulation

\begin{tabular}{lll}
\hline Variable & $\begin{array}{l}\text { Frequency } \\
(\mathbf{n = 4 0 0 )}\end{array}$ & $\begin{array}{l}\text { Percentage } \\
\mathbf{( \% )}\end{array}$ \\
\hline Somaliland's regulation against drug distribution and sales & & 35.1 \\
Reliable & 140 & 28 \\
Unreliable & 112 & 36.8 \\
Poor & 147 & 37 \\
Unprescribed drugs use can be prevented through & 148 & 56.8 \\
Rule and regulation & 227 & 6 \\
Health education & 24 & 71.1 \\
Both & & 23.1 \\
Opinion about use of unprescribed drugs in Hargeisa City & 284 & 2 \\
Stop and prevent using & 92 & 3.5 \\
It is risky & 8 & \\
It is normal & 14 & \\
Government must control & & \\
\hline
\end{tabular}


Table 5. Respondent's practices of unprescribed drugs

\begin{tabular}{lll}
\hline Variable & $\begin{array}{l}\text { Frequency } \\
(\mathbf{n = 4 0 0})\end{array}$ & $\begin{array}{l}\text { Percentage } \\
(\mathbf{\%})\end{array}$ \\
\hline Used any drugs without medical practitioner's prescription & & 64.3 \\
Yes & 257 & 35.5 \\
No & 142 & \\
Used unprescribed drugs more than one time & & 61.3 \\
Yes & 245 & 38.5 \\
No & 154 & 19.6 \\
Types of unprescribed drugs used mostly & & 47 \\
Antibiotics & 78 & 5 \\
Anti pain & 188 & 28.3 \\
Sedatives & 20 & \\
Others & 113 & \\
\hline
\end{tabular}

Table 6. Association of Respondent's use of unprescribed drugs and knowledge of its consequences

\begin{tabular}{|c|c|c|c|}
\hline \multirow[t]{2}{*}{ Variable } & \multicolumn{2}{|c|}{$\begin{array}{l}\text { Unprescribed drug use } \\
\text { status }\end{array}$} & \multirow[t]{2}{*}{ Chi-square } \\
\hline & Yes & No & \\
\hline \multicolumn{4}{|c|}{ Use of unprescribed drugs have side effects to the health } \\
\hline Yes & $\begin{array}{l}204 \\
53\end{array}$ & $\begin{array}{l}100 \\
42\end{array}$ & $\begin{array}{l}4.043^{* *} \text { with } \\
\text { df1 }\end{array}$ \\
\hline
\end{tabular}

\section{CONCLUSION}

The study concluded that there is a high rate of non-prescribed medication use among the Somali Land populations. Easy availability of non-prescribed medication poses major health complications so further research is needed to explore the multiple factors influencing people the use of non-prescribed medication in Somali Land. Furthermore, the law makers should bring up some strict legislations in practice which will prevent the sale of medication over the counter without prescription and there should be proper monitoring and evaluation of the pharmacy services would help to identify the challenges.

\section{CONSENT}

All participants in this study signed a written consent form.

\section{ETHICAL APPROVAL}

The ethical approval was obtained from the Daffodil International University Research Ethics Committee and Ethics Committee of Hargeisa city, Somali Land prior to the start of data collection.

\section{COMPETING INTERESTS}

Authors have declared that no competing interests exist.

\section{REFERENCES}

1. US Food and Drug Administration. Overthe-counter medicines: What's right for you; 2002.

2. Togoobaatar G, Ikeda N, Ali M, Sonomjamts M, Dashdemberel S, Mori R, Shibuya K. Survey of non-prescribed use of antibiotics for children in an urban community in Mongolia. Bulletin of the World Health Organization. 2010;88(12): 930-6.

3. Alhomoud F, Aljamea Z, Almahasnah R, Alkhalifah K, Basalelah L, Alhomoud FK. Self-medication and self-prescription with antibiotics in the Middle East-do they really happen? A systematic review of the prevalence, possible reasons, and outcomes. International Journal of Infectious Diseases. 2017;57:3-12.

4. Arafat SY, Hasan MJ, Kabir R. Use and abuse of anti-ulcerants: A perspective from Bangladesh. International Journal of Research Studies. 2017;1(1):56-58. 
5. Holloway K, Van Dijk L. The world medicines situation 2011-rational use of medicines. Geneva: WHO; 2011.

6. Shehadeh M, Suaifan G, Darwish RM, Wazaify M, Zaru L, Alja'fari S. Knowledge, attitudes and behavior regarding antibiotics use and misuse among adults in the community of Jordan. A pilot study. Saudi Pharmaceutical Journal. 2012;20(2):12533.

7. Napolitano F, Izzo MT, Di Giuseppe G, Angelillo IF. Public knowledge, attitudes, and experience regarding the use of antibiotics in Italy. PloS One. 2013;8(12): e84177.
8. UNICEF \& European Union. The Private sector and health: A survey of Somaliland private pharmacies; 2009.

9. Republic of Somaliland Ministry of Health. $2^{\text {nd }}$ Edition. 2011;1-48.

10. Wu LT, Pilowsky DJ, Patkar AA. Nonprescribed use of pain relievers among adolescents in the United States. Drug and alcohol dependence. 2008;94(1):1-1.

11. Yu M, Zhao G, Lundborg CS, Zhu Y, Zhao $\mathrm{Q}, \quad \mathrm{Xu}$ B. Knowledge, attitudes, and practices of parents in rural China on the use of antibiotics in children: A crosssectional study. BMC Infectious Diseases. 2014;14(1):112.

(c) 2018 Farah et al.; This is an Open Access article distributed under the terms of the Creative Commons Attribution License (http://creativecommons.org/licenses/by/4.0), which permits unrestricted use, distribution, and reproduction in any medium, provided the original work is properly cited.

Peer-review history:

The peer review history for this paper can be accessed here: http://www.sciencedomain.org/review-history/27869 